\title{
Sistema Eletrônico do Serviço de Informação ao Cidadão (e-SIC) e sua contribuição para a transparência: uma experiência gerencial em uma universidade federal
}

Raoni Gonçalves Maciel ${ }^{I}$

https://orcid.org/0000-0003-0346-3943

Platini Gome Fonseca ${ }^{\text {II }}$

Francisco Ricardo Duarte ${ }^{\text {III }}$

Ernani Marques dos Santos ${ }^{\text {IV }}$

${ }^{I}$ Universidade Federal do Vale do São Francisco, PE, Brasil.

Mestre em Administração.

II Universidade Federal da Bahia, Salvador, BA, Brasil.

Doutorando em Administração.

${ }^{I I I}$ Universidade Federal do Vale do São Francisco, PE, Brasil.

Doutor em Difusão do Conhecimento pela UFBA.

Professor adjunto III.

${ }^{I V}$ Universidade Federal da Bahia, Salvador, BA, Brasil.

Pós-doutor em Administração pela Universidade de São Paulo.

http://dx.doi.org/10.1590/1981-5344/3824

Este trabalho teve como objetivo analisar como o Sistema Eletrônico do Serviço de Informação ao Cidadão (e-SIC) contribui com a transparência em uma universidade federal, atendendo às exigências da Lei de Acesso à Informação (LAI). Para isso, pesquisou-se, de forma exploratória, através de documentos e entrevista semiestruturada com gestores de nível estratégico da instituição. O modelo de análise foi construído a partir da LAI e é composto por 3 (três) dimensões (Responsabilidades; Conteúdo e divulgação; Meios e mecanismos) com 19 componentes. Os principais resultados indicam que as dimensões de Responsabilidade e de Conteúdo e divulgação foram as que receberam mais 
contribuição do e-SIC para a ampliação da transparência pública. Os gestores compreenderam a relevância do eSIC para a construção da transparência, contribuindo para a acessibilização das informações e prazos de retorno às manifestações registradas no sistema, colocando a referida universidade como instituição que se encontra em processo de consolidação das práticas de acesso à informação. Entretanto, apesar dos avanços implementados, ainda é possível vislumbrar gargalos que impedem a plena definição da transparência.

Palavras-chave: Transparência pública. e-SIC. LAI. Universidade.

\section{The Electronic System of the Citizen Information Service (e-SIC) and its contribution to transparency: a management experience at a federal university}

The objective of this study was to analyze how the Electronic System of the Citizen Information Service (eSIC) contributes to transparency in a federal university, meeting the requirements of the Law on Access to Information (LAI). For this, it was investigated, in an exploratory way, through documents and semi-structured interviews with managers of the institution's strategic level. The analysis model was constructed from LAI and consists of 3 (three) dimensions (Responsibilities, Content and dissemination, Means and mechanisms) with 19 components. The main results indicate that the dimensions of Responsibility and Content and dissemination were those that received the most contribution of e-SIC to the increase of public transparency. The managers understood the relevance of the e-SIC to the construction of transparency, contributing to the accessibility of information and deadlines of return to the manifestations registered in the system, placing the aforementioned university as an institution that is in the process of consolidating the practices of access to information. However, despite the advances made, it is still possible to envisage bottlenecks that prevent the full definition of transparency. 
Keywords: Public transparency. e-SIC. LAI. University.

Recebido em 26.11.2018 Aceito em 29.03.2019

\section{Introdução}

O avanço da tecnologia evidenciou a ampliação de diversos caminhos, inclusive para o fortalecimento das novas abordagens de gerenciamento e de controle por parte da sociedade. Com a modernização dos processos e cultura da gestão pública, a assimetria de informação, um indicador que torna o saber institucional acessível, deixa de ser uma característica exclusiva e passa a ser aberta e de interesse público (CRUZ et al., 2012).

Nesse sentido, tem-se buscado implementar instrumentos para que as informações que versem sobre a plena satisfação dessas necessidades sejam acessibilizadas e facilitadas. Por exemplo: a Lei no 12.527 - Lei de Acesso à Informação (LAI), foi implementada na Administração Pública Federal (APF) a partir do Decreto no 7.724 de 16 de maio de 2012. A LAI regulamenta o direito de acesso às informações públicas. Esta entrou em vigor, criando mecanismos que possibilitam, a qualquer pessoa, física ou jurídica, sem a necessidade de apresentar motivo, o recebimento de informações públicas dos órgãos.

Como ferramenta para efetivar os direitos, deveres e responsabilidades elencados no dispositivo legal acima, foi criado o Sistema Eletrônico do Serviço de Informação ao Cidadão - e-SIC, o instrumento que potencializa os recursos de acesso da sociedade à informação, movendo os gestores e servidores públicos para um melhor desempenho das atividades da gestão pública e, ao mesmo tempo, possibilite à comunidade acesso às informações substanciais ao exercício de seus direitos (CORDEIRO et al., 2012).

Para Carli e Fachin (2016), o E-SIC é de um sistema online que integra, reúne e sistematiza dados públicos para subsidiar a gestão da informação, ainda mais quanto às estratégias ou à definição das políticas públicas que promovam as vantagens para toda a sociedade e instituição. Trata-se de um sistema que funciona na Internet e centraliza todos os pedidos de informação amparados pela LAI (PORTELA; CORTÊS, 2015). Assim, o e-SIC permite que qualquer pessoa física (PF) ou jurídica (PJ) possa encaminhar os pedidos de acesso à informação pública, acompanhar o prazo e receber a resposta da solicitação realizada para os órgãos e entidades dos Poderes por meio virtual.

Ainda dentro da referida LAI, importante se faz destacar que há uma previsão legal que versa sobre a questão dos instrumentos de divulgação da informação pública e o seu acesso. O Capítulo II - Do acesso às informações e sua divulgação, art. $6^{\circ}$ ao $9^{\circ}$, evoca sobre a importância de se estabelecer nos órgãos e entidades públicas os critérios e também 
componentes para gestão transparente. Essa exigência explica o debate que ocorre, nos órgãos públicos, sobre implementação de sistemas que possam contribuir para a acessibilidade e transparência, inclusive nas universidades públicas (GAMA et al., 2017).

Como unidade de análise, a pesquisa ocorreu na Universidade Federal do Vale do São Francisco (Univasf), lócus em que se notou, preliminarmente, o papel que o e-SIC desempenhava na consecução das atividades de acesso às informações públicas e transparência, apesar dos alguns desafios no processo de tratamento e tramitação desses dados, 0 que significativamente trouxe uma reflexão acerca da necessidade de se analisar essas questões sob ótica desta instituição, razão pela qual se constitui esta a justificativa teórica do estudo.

Autores como Souza et al. (2013), Raupp e Pinho (2014) e Angeli (2016), debruçaram-se sobre a transparência e da LAI, discutindo vieses que fundamentam papel da sociedade perante desafios apresentados pela gestão. Destaca-se o fato de que os autores discutem, sob a ótica da transparência em sistemas eletrônicos de informação, o papel da gestão da informação públicas para a divulgação e acessibilidade à sociedade das ações e propostas que são desenvolvidas e implementadas na gestão pública, possibilitando ao cidadão as ferramentas de controle, de acesso e fiscalização de políticas.

Dessa forma, a pesquisa partiu da seguinte pergunta: de que forma o e-SIC contribui com a transparência pública na Univasf, atendendo às exigências da LAI? Nesse contexto, surge o seguinte objetivo: analisar como o e-SIC contribui com a transparência na referida instituição, atendendo as exigências da LAI. Para alcançar o objetivo central, foram definidos os seguintes objetivos específicos: identificar os aspectos que possibilitam o atendimento da LAI, que contribuem com a transparência pública no âmbito da Univasf; levantar as iniciativas de gestão, com foco na transparência no ambiente organizacional da Univasf; e analisar de que maneira os gestores utilizam o Sistema Eletrônico do Serviço de Informação ao Cidadão (e-SIC) na Univasf.

\section{Referencial teórico}

\subsection{Transparência pública}

A transparência é praticada no contexto das organizações, sejam elas públicas ou privadas, enquanto vertente direciona-se a atividades de prestação de contas do Estado, em virtude dos princípios legais da gestão, especialmente quanto à publicidade de seus atos administrativos.

No âmbito das organizações, a transparência deve ser um elemento estratégico e que dimensione vantagem competitiva em um ambiente, onde a sociedade deve participar do processo de conhecimento das ações de um ente organizacional, ainda mais aqueles que gerenciam os recursos (FIGUEIREDO; SANTOS, 2013). 
Segundo Medeiros, Magalhães e Pereira (2013), a prestação de contas efetivas e transparentes são desafios para as organizações contemporâneas, uma vez que há uma disputa acirrada pela confiabilidade e credibilidade em qualquer campo de atuação. É, então, a transparência que vai conferir, às instituições que gerenciam recursos, o compromisso de viabilizar, à sociedade, as formas e onde são aplicados os aportes.

Nesse sentido, a transparência pública objetiva mostrar a atuação das empresas e de seus agentes públicos que desempenham serviços e atividades em seu nome, enquanto fenômeno de prestação de contas públicas (ROCHA, 2013). Medeiros, Magalhães e Pereira (2013) exemplificam que existem duas abordagens de accountability - conceito mais amplo que a transparência compõe: prestação de contas, que se refere à forma, ao destino, à distribuição e uso eficiente dos recursos financeiros, e prestação de contas não financeira, que são relatórios nos quais se define a programação das atividades realizadas pelas instituições públicas.

Espera-se dos órgãos e entidades da gestão pública que, em caráter geral, sejam apresentadas as destinações dos recursos em compatibilidade com demandas da comunidade, gerando impactos no desenvolvimento social. Uma vez disponibilizada ao público, a informação deve ter 0 acesso facilitado, em meios digitais, preferencialmente. Segundo Coelho (2001), compreende-se que as empresas, em seus processos de desenvolvimento produtivo, devem levar informações do seu progresso a um patamar de sociedade, uma vez que, quando acessibilizados, dados organizacionais possibilitam o controle social e, posteriormente, o exercício da fiscalização.

Para efeitos de análise do contexto conceitual da transparência pública, considerou a proposição teórica de Medeiros, Magalhães e Pereira (2013), uma vez que esta parece ser a que mais se aproxima da proposta e de objetivos da Gestão Pública.

\subsection{Sistemas eletrônicos de informação ao cidadão (e- SIC)}

A concepção de governo eletrônico, embora associada ao uso de tecnologia de informação no setor público, ultrapassa essa dimensão. Em alguns casos, está vinculada à modernização da administração pública por meio do uso de TICs e comunicação e na melhoria da eficiência dos processos operacionais e de gestão (DINIZ et al., 2009).

O governo eletrônico é constituído conceitualmente como as atividades ligadas à sistematização e acessibilidade de serviços e informações a partir do uso dos recursos tecnológicos. É considerado política pública com reflexo na gestão, onde cidadãos e organizações buscam acesso a informações públicas para se subsidiar tomada de decisão ou acionar os instrumentos fiscalizatórios (SANTOS, 2008; BARBOSA, 2017). Por exemplo, o e-SIC permite o registro de reclamações referentes aos pedidos realizados e de recursos em até quatro instâncias. 
Os recursos são formalizados no prazo de 10 (dez) dias, a partir do recebimento da resposta da solicitação no sistema.

O e-SIC é um sistema que funciona na Internet e centraliza todos os pedidos de informação que forem dirigidos ao Poder Executivo Federal, as respectivas vinculadas e empresas estatais (VIEIRA; MONTENEGRO JUNIOR, 2016). O sistema eletrônico de informação ao cidadão é, no âmbito do Governo Federal, regulamentado pela Lei de Acesso à Informação (LAI) e amparado pelo Decreto $n^{\circ} 7.724 / 2012$, que traz os fundamentos da transparência ativa da administração pública. Desde a sua implantação, o e-SIC tem desempenhado um importante papel, estabelecendo uma ponte entre os órgãos e entidades da gestão pública e a sociedade, contribuindo para o fortalecimento das ações de acesso à informação pública e relevante para subsidiar a tomada de decisão e os mecanismos de fiscalização.

Isso se reflete nas estatísticas recentes apontadas no próprio E-SIC. Segundo dados levantados no sistema eletrônico, em 2017, foram registrados 121.526 pedidos, com média mensal de 10.128 pedidos. Do total de pedidos, um percentual de 99,36\% foram respondidos dentro do prazo estabelecido para acesso aos dados e às informações de caráter público, que é, atualmente, de 15 dias úteis (e-SIC, 2018). Com isso, o tempo médio de resposta é de 13 dias, mas com um percentual de prorrogação de 10,10\%. Dos pedidos, 95,26\% corresponde a pessoas físicas e 4,74\%, à pessoa jurídica.

Uma análise detalhada aponta que, dos assuntos mais requisitados pelos cidadãos ávidos por informação pública, percentual de 12,89\% destina-se aos pedidos sobre orçamento e finanças (e-SIC, 2018). Além disso, assuntos sobre o Governo e Gestão Pública representam 12,10\% dos pedidos.

\subsection{Lei de acesso à iinformação (LAI): visão sobre transparência pública e os sistemas de informação}

A Lei no $12.527 / 11$, conhecida na perspectiva da gestão pública e da sociedade como a Lei de Acesso à Informação (LAI), é, pois, um avanço significativo em matéria de transparência pública e tratamento dos dados referentes às informações de interesse coletivo e serviço de informações a cidadãos, ao evidenciar que qualquer interessado possa ter acesso facilitado a informações oriundas de órgãos e instituições públicas (MARTINS, 2012).

O direito de acesso à informação é diagnosticado mediante disposto no art. 5. ${ }^{\circ}$, XXXIII, da Constituição Federal de 1988, que garante a todos o direito de receber dos órgãos públicos informações de seu interesse particular ou de interesse coletivo ou geral, ressalvadas a garantia de sigilo daquelas que sejam imprescindíveis à segurança da sociedade e o Estado (JUSTEN FILHO, 2014).

É nesse aspecto que a Lei n. ${ }^{\circ} 12.527 / 2011$ representa um importante instrumento de democratização e plena legitimação dos atos 
da administração pública, a partir da implementação de instrumentos de acesso à informação facilitada que estimulem a participação e o controle da sociedade civil na tutela dos direitos individuais e coletivos. Logo, o Capitulo II, denominado "Do acesso às informações e da sua divulgação", conta com três artigos nesse sentido. Especificamente o artigo $6^{\circ}$ denota as responsabilidades de órgãos e entidades do Poder Público, os artigos 70 e $8^{\circ}$ dispõem sobre o conteúdo do acesso à informação e artigo 90 explicita os meios e os mecanismos de divulgação da informação.

Um estudo de Cavalcanti, Damasceno e Veras de Neto (2013) reflete sobre a transparência pública nos sítios eletrônicos das autarquias federais - sem fazer parte do seu objeto de estudo, o e-SIC, destacando a elaboração de dimensões e componentes da transparência pública por meio da concepção dos mesmos sobre os artigos supramencionados da LAI. Foi a partir de Cavalcanti, Damasceno e Neto (2013) que o modelo de análise dessa pesquisa passou a ser construído.

Os autores adaptaram as variáveis do modelo com o objetivo de analisar a conformidade do acesso à informação das instituições com a lei, a partir de pesquisa exploratória, descritiva com o método quantitativo, cujo instrumento é uma listagem de verificação, dos sítios eletrônicos das autarquias federais com relação à LAI (CAVALCANTI; DAMASCENO; NETO, 2013). Nesse sentido, foi a partir de dimensões e componentes que 0 modelo de análise dessa pesquisa passou a ser construído.

Ressalte-se que incisos do art. $6^{\circ}$ explicitam as duas responsabilidades, quais sejam, a gestão transparente da informação e a proteção da informação. Ademais, observa-se no artigo 70, especificamente sobre o conteúdo do acesso à informação, que é direito do cidadão obter informação primária, íntegra, autêntica e atualizada. Além disso, o dispositivo acima garante solicitações de informação ligadas às atividades exercidas pelos órgãos e entidades, inclusive relativas à política, organização e serviços pertinentes à administração pública, utilização de recursos, licitação, contratos (RAUPP; ABREU; ABREU, 2015).

Com base nas disposições dos artigos $8^{\circ}$ e 90, há meios e mecanismos de divulgação da informação, além de requisitos de legalidade, tal como 0 registro das competências e estrutura organizacional, endereços e telefones das respectivas unidades e quanto horários de atendimento ao público.

Enquanto finalidade das organizações e entidades de caráter público, a gestão de forma transparente encontra-se mais praticada e estimulada, tendo em vista os argumentos da participação da sociedade no processo de alocação dos recursos, assim como da construção dos componentes sociais de desenvolvimento. Essas informações devem ser acessibilizadas ao público de interesse, tornando meios e caminhos facilitados e entendimento simplificado; deve trazer em sua essência a responsabilidade de levar a informação de suas ações a quem de direito, protegendo o acesso às informações sigilosas e zelando pela segurança jurídica e contextual (RAUPP; ABREU; ABREU, 2015). 
A dimensão que trata do conteúdo do pedido, amparado pelo art. $7^{\circ}$ da LAI, traduz-se preferencialmente, enquanto:

I - orientação sobre procedimentos para a consecução de acesso, bem como sobre o local onde poderá ser encontrada ou obtida a informação almejada;

II - informação em registros ou documentos, produzidos ou acumulados por seus órgãos ou entidades, recolhidos ou não a arquivos públicos;

III - informação produzida ou custodiada por pessoa física ou por entidade privada decorrente de qualquer vínculo com seus órgãos ou entidades, mesmo que esse vínculo já tenha cessado;

IV - informação primária, íntegra, autêntica e atualizada;

V - informação sobre as atividades exercidas pelos órgãos e entidades, inclusive as relativas à sua política, organização e serviços;

VI - informação pertinente à administração do patrimônio público, utilização de recursos públicos, licitação, contratos administrativos; e

VII - informação relativa:

a) à implementação, acompanhamento e resultados dos programas, de projetos e ações dos órgãos e entidades públicas, bem como metas e indicadores propostos;

b) ao resultado de inspeções, de auditorias, prestações e tomadas de contas realizadas pelos órgãos de controle interno e externo, incluindo as prestações de contas relativas a exercícios anteriores.

Exceto informações consideradas pela gestão pública como sigilosas, os dados e demais níveis de interesse social deverão ser acessibilizados ao público, em forma íntegra, por meio de requerimentos, com detalhamento da justificativa e ajuizamento do pedido, devendo, por sua vez, órgãos e entidades acessibilizar de forma imediata a consulta, fiscalização e os estudos, sob pena de responsabilização (LOPES, 2006; JARDIM, 2013).

Quanto à terceira dimensão/agrupamento, discute-se a acessibilidade dos dados e informações à sociedade por meio de mecanismos facilitadores, onde as pessoas com 0 interesse de ter conhecimento sobre tema da alçada da gestão pública devem ter a sua disposição os recursos que viabilizem essa prática (ANGÉLICO, 2012). Hoje, as informações públicas, em geral, versam sobre destinação de recursos, impacto das políticas públicas, repasses e transferências, parcerias público-privadas, acompanhamento de programas sociais, dentre outros. Assim, apresenta-se o modelo de análise da pesquisa (Quadro 1) - adaptado de Cavalcanti, Damasceno e Neto (2013): 
Quadro 1 - Modelo de análise

\begin{tabular}{|c|c|c|}
\hline ART. & DIMENSÕES & COMPONENTES \\
\hline \multirow{3}{*}{$6^{\circ}$} & \multirow{3}{*}{ Responsabilidade } & $\begin{array}{l}\text { R1 - Garantia de amplo acesso à informação e ampla } \\
\text { divulgação }\end{array}$ \\
\hline & & $\begin{array}{l}\text { R2 - Proteção da informação, garantindo-se sua } \\
\text { disponibilidade, autenticidade e integridade }\end{array}$ \\
\hline & & R3 - Proteção da informação sigilosa \\
\hline \multirow{13}{*}{$7^{\circ}$ e $8^{\circ}$} & \multirow{13}{*}{$\begin{array}{l}\text { Conteúdo e } \\
\text { divulgação }\end{array}$} & CD 1 - Procedimentos para a consecução de acesso \\
\hline & & CD 2 - Contida em registros ou documentos \\
\hline & & CD 3 - Produzidas com terceiros \\
\hline & & CD 4 - Primária, íntegra, autêntica e atualizada \\
\hline & & CD 5 - Atividades exercidas pelos órgãos e entidades \\
\hline & & CD 6 - Pertinente à administração do patrimônio público \\
\hline & & $\begin{array}{l}\text { CD } 7 \text { - Projetos, programas e ações dos órgãos e entidades } \\
\text { públicas }\end{array}$ \\
\hline & & CD 8 - Resultado de inspeções, auditorias \\
\hline & & CD 9 - Competências e estrutura organizacional \\
\hline & & $\begin{array}{l}\text { CD } 10 \text { - Quaisquer repasses ou transferências de recursos } \\
\text { financeiros }\end{array}$ \\
\hline & & CD 11 - Registros das despesas \\
\hline & & CD 12 - Procedimentos licitatórios \\
\hline & & $\begin{array}{l}\text { CD } 13 \text { - Dados gerais para o acompanhamento de programas } \\
\text { CD } 14 \text { - Respostas a perquntas mais frequentes da sociedade }\end{array}$ \\
\hline \multirow{2}{*}{$9^{\circ}$} & \multirow{2}{*}{$\begin{array}{c}\text { Meios e } \\
\text { mecanismos }\end{array}$} & MM 1 - Espaço físico para fornecer informações ao cidadão \\
\hline & & MM 2 - Audiências ou consultas públicas \\
\hline
\end{tabular}

Fonte: Elaboração própria, a partir de Cavalcanti, Damasceno e Neto (2013).

\section{Metodologia da pesquisa}

A investigação, de natureza qualitativa, usou a abordagem de Estudo de Caso. Para isso, buscaram-se exames teóricos e de campo acerca do e-SIC e a transparência, sobremaneira a experiência da Univasf, em observância à LAI - com foco no processo de gestão. O Estudo de Caso enquadra-se como uma abordagem qualitativa e é utilizado para a coleta de dados e informações, ou seja, faz-se diagnóstico do ambiente, buscando levantar dados que sejam de significativa relevância para o pesquisador (YIN, 2015).

Para a coleta dos dados, foram realizadas entrevistas, com auxílio de roteiro de entrevista semiestruturada, com 7 (sete) gestores, sendo eles da Pró-Reitoria de Assistência Estudantil (PROAE), Pró-Reitoria de Extensão (PROEX), Pró-Reitoria de Ensino (PROEN), Pró-Reitoria de Orçamento e Gestão (PROGEST), Pró-Reitoria de Pesquisa, de PósGraduação e de Inovação (PRPPGI), Pró-Reitoria de Planejamento e de Desenvolvimento Institucional (PROPLADI) e Superintendência de Gestão de Pessoas (SGP), sendo o procedimento de análise dos dados a 
estratégia de leitura analítica das transcrições. O roteiro de entrevista foi elaborado a partir do modelo teórico de análise adaptado, com observância de 3 (três) dimensões (Responsabilidade; Conteúdo e divulgação; Meios e mecanismos) e 19 componentes.

O roteiro foi validado em agosto de 2018. As entrevistas ocorreram em setembro de 2018. O tempo de duração total da realização do roteiro de entrevistas foi de $3 \mathrm{~h} 21 \mathrm{~min} 15 \mathrm{~s}$ foram gravadas por meio de aparelho eletrônico. As entrevistas foram realizadas nos gabinetes dos gestores com privacidade e agendamento de horário, todos os gestores assinaram o Termo de Consentimento Livre e Esclarecido (TCLE). O processo de transcrição das entrevistas resultou em, para fins de análise, 55 páginas. Por sua vez, o projeto de pesquisa foi aprovado pelo Comitê de Ética em Pesquisa da Univasf.

De forma complementar, foi realizada uma pesquisa documental. Logo, para este fim, foram analisados os documentos em questão: Manuais, Leis, Decreto no 7.724/2012, o fluxograma dos pedidos de acesso à informação, os relatório estatísticos do e-SIC da Univasf e outros.

A implementação do e-SIC na Univasf foi efetivada por meio de ações de servidores que fizeram cadastros no sistema e iniciaram as atividades do sistema, tendo em vista que, além de protocolar o pedido, o sistema eletrônico permite acompanhar o prazo pelo número de protocolo gerado e, também, receber a resposta da solicitação por e-mail; entrar com os recursos cabíveis a cada tipo de solicitação, apresentar as reclamações e consultar as respostas. O e-SIC foi instaurado pela Portaria Normativa no 01, de 29 de maio de 2012, sendo, pois, o setor responsável por receber, registrar e responder os pedidos de acesso à informação com base na LAI; atender e orientar o público quanto ao acesso à informação, assim como informar sobre tramitação de documentos da instituição; e nos campi da Univasf atender a demandas específicas da atividade de registro acadêmico e apoio ao discente.

A elaboração do modelo de análise (Quadro 1 ) desta pesquisa foi efetivada com base nos artigos $60,70,8^{\circ}$ e 90 , todos do Capítulo II da LAI, além da investigação de Cavalcanti, Damasceno e Neto (2013) que construíram os indicadores com os artigos supramencionados para analisar a conformidade dos sítios eletrônicos das autarquias federais com relação à LAI por meio de listagem de verificação.

A pesquisa foi desenvolvida por meio da execução de 3 (três) etapas, a saber: a identificação de aspectos da LAI na contribuição com transparência pública nas universidades, com levantamento de cunho teórico-conceitual em plataformas de pesquisa (Google Acadêmico, Scopus, Scielo, Spell e Banco de Teses e de Dissertações da Capes); o levantamento das iniciativas de gestão e transparência na universidade em estudo; e a análise da forma que os gestores utilizam o e-SIC na instituição.

\section{Discussão e análise dos dados}


As universidades públicas, na qualidade de órgão atuante da gestão pública, encontram-se, nesse sentido, atreladas às concepções e a respaldos trazidos pela Lei de Acesso à Informação (LAI), uma vez que, em razão das finalidades a que atendem no mundo social, produzem informações que são de interesse da coletividade, devendo, para tanto, atentarem-se para as mudanças e transformações digitais, utilizando recursos eletrônicos em favor das diversas configurações em seus modelos de comunicação com a comunidade e de gestão da informação pública, diferenciando, inclusive, aquelas de origem pública ou sigilosa, reconhecendo a validade e valor daquelas para os cidadãos formularem suas estratégias e seus processos decisórios e a segurança e proteção destas, zelando pela autonomia na preservação dos dados privados (GAMA; RODRIGUES, 2017).

Verifica-se, nesses ambientes, que a promoção da transparência e do acesso à informação são práticas e funções indispensáveis para possibilitar que o poder público seja exercido de forma aberta e que os cidadãos possam acompanhar, avaliar e ajudar no controle da gestão daquilo que é público, por meio de canais de diálogo abertos com os gestores institucionais, ao passo que podem contribuir com a execução das medidas e políticas publicas necessárias ao progresso, bem como conferir e acompanhar emprego eficiente de recursos financeiros para 0 investimento em ações estratégicas de relevante interesse público. Ademais, para dar enfoque a esse esforço, as instituições públicas, buscando adequarem os sistemas de informação, passaram a implementarem ações e práticas que evidenciassem a transparência pública por meio de uma nova abordagem conhecida como e-SIC.

Essas particularidades podem ser observadas na estrutura de acesso à informação dentro da Univasf, considerando o papel que o e-SIC exerce sobre o processo de construção de transparência na Univasf. A seguir, o Quadro 02 (Consolidado com contribuições do e-SIC para a transparência pública na Univasf, com base nos gestores), em combinação com a Figura 01 (Média das dimensões e das contribuições do e-SIC com a LAI na instituição), aponta o consolidado, com base no modelo de análise, que evidencia a percepção dos gestores sobre dimensões e componentes da transparência e como o E-SIC contribui para a construção dessas dimensões.

Quadro 2 - Consolidado com contribuições do e-SIC para a transparência pública na Univasf, com base nos gestores respondentes da pesquisa 


\begin{tabular}{c|c|c|c|c|} 
& & CF & CP & NC \\
\hline 1 & R1 & 7 & 0 & 0 \\
\hline 2 & R2 & 6 & 1 & 0 \\
\hline 3 & R3 & 7 & 0 & 0 \\
\hline 4 & CD1 & 7 & 0 & 0 \\
\hline 5 & CD2 & 6 & 1 & 0 \\
\hline 6 & CD3 & 2 & 3 & 0 \\
\hline 7 & CD4 & 6 & 1 & 0 \\
\hline 8 & CD5 & 6 & 1 & 0 \\
\hline 9 & CD6 & 1 & 1 & 4 \\
\hline 10 & CD7 & 7 & 0 & 0 \\
\hline 11 & CD8 & 1 & 5 & 0 \\
\hline 12 & CD9 & 7 & 0 & 0 \\
\hline 13 & CD10 & 0 & 2 & 4 \\
\hline 14 & CD11 & 0 & 1 & 5 \\
\hline 15 & CD12 & 1 & 0 & 5 \\
\hline 16 & CD13 & 6 & 1 & 0 \\
\hline 17 & CD14 & 6 & 0 & 0 \\
\hline 18 & MM1 & 6 & 0 & 0 \\
\hline 19 & MM2 & 0 & 0 & 5 \\
\hline
\end{tabular}

Fonte: dados da pesquisa.

Aqui, para fins de identificação acerca das contribuições do e-SIC para a definição da transparência pública na Univasf, lê-se CF (contribuição forte), CP (contribuição parcial) e NC (não contribui). Do Quadro 02 citado, os números distribuídos decorrem da apreciação dos respondentes sobre as dimensões e componentes. Embora tenha sido realizada a pesquisa com 7 (sete) gestores, que desencadearia um igual número de marcações, cumpre destacar que, em determinados pontos da tabela, os gestores indicaram que certos componentes do modelo de análise não se aplicavam aos seus setores, não atribuindo juízo de valor sobre eles.

A seguir, a Figura 01 demonstra a média das dimensões e das contribuições do e-SIC com a LAI, na Univasf.

Figura 1 - Média das dimensões e das contribuições do e-SIC com a LAI na instituição

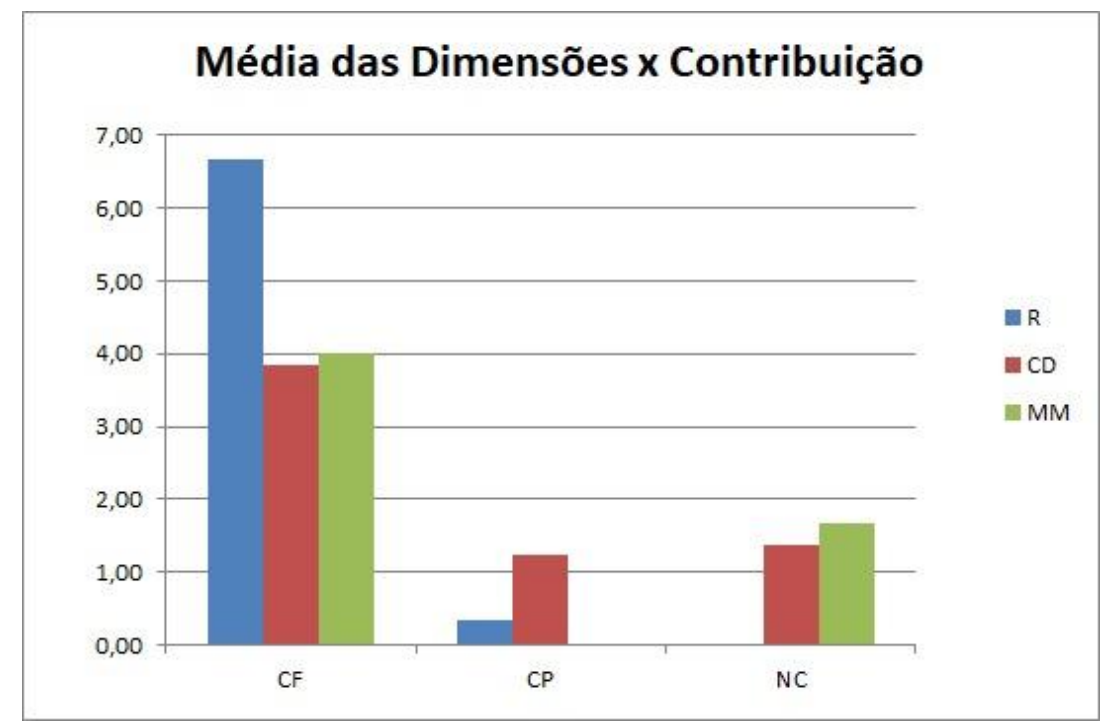

Fonte: dados as pesquisa

Com relação à primeira dimensão, a Responsabilidade, denota-se, em linhas gerais, a tendência de "forte contribuição" do e-SIC na 
construção da transparência pública na Univasf, em conformidade com os preceitos da LAI, já que existe, por parte dos gestores e equipes de trabalho, o comprometimento em disponibilizar aos cidadãos interessados nas atividades e programas a partir das tecnologias o teor integral das informações (ZORZA; RODRIGUES; GAMA, 2018). A garantia de acesso à informação e aos instrumentos de divulgação, ao que se ficou observado da comparação do quadro consolidado, trata-se de preocupação dos gestores (P1 a P7).

Assim, com base na LAI, as instituições e os órgãos públicos devem realizar atualizações periódicas dos seus sítios institucionais e dos sistemas de acesso ao cidadão via e-SIC, facilitando o processo por meio de abertura de canais de interação e diálogo para a solução de questões sociais e duvidas sobre o processo de gestão pública dos recursos, seja pela divulgação de informações ou concessão de dados por demanda da sociedade, desde que não sejam sigilosas, conforme a Tabela 1, a partir de uma "forte contribuição" do e-SIC sobre a proteção das informações sigilosas, especialmente no que compete a gestão do dados funcionais, registros de preços, licitação, patentes, tramites judiciais, dentre outros.

Na Univasf, o e-SIC e canais de diálogo, interação e comunicação com a comunidade externa, em geral o e-mail institucional ou demandas que são registradas no sistema integrado de acesso a cidadãos (https://esic.cgu.gov.br/) e o portal institucional são considerados instrumentos substanciais, já que, é por meio desses instrumentos que os gestores conseguem conhecer anseios, demandas, dúvidas, as reclamações e denúncias que provêm da sociedade, contribuindo para o acompanhamento de ações, projetos e investigação de casos omissos.

Pensando com relação à comunidade externa, acredito que a melhor forma de se ter acesso às informações da instituição ou ao setor e, obviamente, de diversos outros parceiros e diversas ações, atividades que a universidade participa, é pelo acesso ao portal. Eu não vejo outro modo mais rápido da comunidade externa, pensando aí que ela pode não saber como é a estrutura organizacional, e quem responde por cada setor de atuação. Eu acredito que aquela ferramenta do modo como ela é posta no portal exatamente é o melhor caminho para ela ter a informação de que o cidadão externo ou também os membros internos precisam (ENTREVISTADO 02).

Quanto à "Proteção da informação, garantindo-se a sua disponibilidade e sua autenticidade", observou-se "forte contribuição" por parte de $85,7 \%$ dos gestores, evidenciando que, além de contribuírem para a disponibilização das informações nos canais de informação da Univasf, os gestores zelam pela segurança integral, pela sua autenticidade e completude dos dados publicados.

Para grande parte dos gestores, ainda é baixo o número de registros e de solicitações que chegam via e-SIC, mas, quando surgem, essas demandas são colocadas como fundamentais para manifestação de retorno, considerando os prazos para a resposta fundamentada e clara, 
que é, hoje, segundo a LAI, de 10 (dez) dias úteis (ROCHA, 2013; RODRIGUES; MARCONDES, 2018).

Quanto à dimensão "Responsabilidade" e aos seus componentes, ficou evidente a contribuição predominante nos padrões de atendimento da LAI, no contexto da universidade, para constituição dos fundamentos centrais da transparência pública. Os dados evidenciam que, em relação às questões da disponibilização ampla, integridade, autenticidade dos canais e informações públicas e segurança e proteção de dados de caráter sigiloso (ROCHA, 2013), os setores institucionais encontram-se compatíveis com o que motiva a LAI, de forma que o e-SIC trouxe contribuições para essa dimensão.

Por conta do modelo de análise, a dimensão "Conteúdo e Divulgação" é a que determina maior peso, em função do número de componentes. Quanto ao componente "Procedimentos para a consecução dos acessos", tornou-se clara, por meio da análise do quadro consolidado, uma "forte contribuição" dos setores da instituição na definição e construção das políticas de transparência. Para os gestores, os procedimentos para acesso ao e-SIC propiciam, tanto a sociedade quanto aqueles que atuam no exercício da função, tendo em vista o reconhecimento das contribuições para a observância de melhorias no regime de acolhimento, no tratamento, filtragem e retorno das demandas importantes registradas pelos cidadãos.

Nesse sentido, percebem-se benefícios de aplicar fundamentos do eSIC no tratamento das informações para os setores administrativos e na gestão da tramitação das informações de interesse coletivo, tal qual fica evidente no trecho da entrevista abaixo:

Vantagens de ter o e-SIC como mecanismo de obtenção de informação, anteriormente, como é que eram os pedidos de acesso à informação. A gente tem muita informação que vinha, a CGU tem muita informação que vinha e até hoje vai pedir sempre, mas é um órgão de controle, mas antigamente alguém pedia uma informação mandava um e-mail, um ofício e tal. E nisso, a gente não se sentia na obrigação de prestar a informação. Você prestava quando tinha disponibilidade ou então você vou prestar mais tarde. Agora não, por conta da Lei da Transparência, eu acho que o e-SIC veio no bojo da Lei do Acesso à informação e da Transparência. Dá mais transparência, tanto a você está desempenhando a função pública, quanto o cidadão comum, que pega essa informação e consegue analisar realmente, se sente atendido como cidadão. Se sente respeitado, principalmente, quando você está atendendo na integridade da informação e talvez da informação mais fácil [...]. (ENTREVISTADO 03)

Quanto às "informações contida em registros ou documentos", $85,7 \%$ dos setores analisados percebem uma "forte contribuição" do sistema. Assim, fica a CGU (Controladoria Geral da União) como um organismo responsável pela cobrança, acompanhamento e punição administrativa para agrupamento das informações contidas em registros e 
em documentos, quando não sigilosos, e a consequente divulgação dos conteúdos para a sociedade.

As informações arquivadas, de caráter público e que apresentem uma relevância social, devem também ser disponibilizadas com a integridade e a autenticidade a partir de meios digitais de fácil e amplo acesso a conteúdos publicados. Ao passo em que se observa uma fase de transição dos arquivos físicos para os instrumentos digitais na universidade federal, ainda assim há algumas isoladas resistências no atendimento de exigências da CGU quanto à disponibilização de documentos arquivados e outros materiais públicos, considerando o volume das informações, o tempo dedicado para a digitalização dos arquivos e o compartilhamento, dentre outros impeditivos da prática.

Faz-se necessário uma cultura de atendimento aos regramentos legais, atentando para os riscos administrativos e de caráter punitivo, inclusive podendo repercutir sobre outras penalizações. No componente "Produzido com terceiros", $28,6 \%$ dos respondentes se manifestaram elementos que indicam uma "forte contribuição" para a construção de transparência na instituição, ao passo que é de $50 \%$ o percentual dos que evidenciaram "contribuição parcial" por meio da observância desse ponto de análise sobre a custódia.

Nesse aspecto, houve algumas discrepâncias em relação aos demais componentes, inclusive no viés da dimensão "Responsabilidade", em que se percebeu uma "forte contribuição" sobre as pessoas físicas (cidadãos) e, nesse sentido, encontram-se pessoas jurídicas (empresas) no exercício de obtenção informações públicas, considerando que estas, em função das características, podem realizar parcerias exitosas e produtivas para ambas.

Em relação ao fato de os setores da universidade disponibilizarem as informações que sejam "Primárias, íntegras, autênticas e atualizadas", $85,7 \%$ concordaram existir reforçada contribuição do componente, segundo a LAI, sendo o percentual compatível com o segundo componente da dimensão "Responsabilidade". O resultado ratifica parte da literatura: não basta divulgar nos meios digitais as informações, elas precisam ser íntegras, autênticas e atualizadas continuamente (ROCHA, 2013; AIROLDI; SIVEIRA, 2015; ).

A segunda e terceira etapas buscaram realizar o levantamento das iniciativas de gestão e transparência na Univasf, bem como analisar a forma que os gestores utilizam o e-SIC. Os dados coletados nessas fases permitiram uma consideração sobre esse componente: ao analisar os sítios institucionais de alguns setores, a atualização das informações não se encontra condizente com o que foi exposto pelos gestores. Assim, é possível encontrar dados e notícias desatualizadas, orçamentos antigos e diversos registros obsoletos, por falta de manutenção dos dados, o que, mais uma vez, reforça a importância do e-SIC e sua forte contribuição para que os cidadãos tenham acesso a dados mais recentes sobre as práticas de gestão executadas pela Univasf. 
Em relação a "atividades exercidas por órgãos e por entidades", $75,8 \%$ evidenciam uma "forte contribuição" do e-SIC, considerando que os serviços prestados pelos setores demandam, em caráter peculiar, questionamentos acerca da qualidade e eficiência das atividades e das funções desempenhadas no contexto da gestão pública, ensejando transparência. Quanto a "patrimônio público", observou-se que 71,4\% dos setores não reconhecem a contribuição das imposições da LAI na construção de transparência, ou seja, é baixo o conhecimento e a atuação da LAI no que compete a mecanismos de proteção e preservação do patrimônio público, ficando os recursos em geral limitados e esquecidos pelas ações e práticas de prestação de contas.

Foi questionado aos gestores se os setores dispunham de dados contábeis e orçamentários, como a descrição de receitas, de despesas, dos procedimentos licitatórios, o que gerou retornos positivos. A análise aos sítios institucionais revelou discrepâncias na divulgação de informações ou sua atualização para dados mais recentes, oportunizando o acompanhamento pelos cidadãos e por órgãos interessados na participação das licitações.

Com a disparidade entre as respostas dos gestores administrativos e da realidade vista na prática nos sítios institucionais, concebeu-se a percepção de que ainda há muito o que avançar no pleno atendimento às questões exigidas pela LAI no que tange à constituição das práticas de transparência pública, o que reforça a forte contribuição do e-SIC nesse sentido, colocando para alguns setores da universidade a necessidade de promoverem adequações com os requisitos da lei (ANGÉLICO, 2012; ROCHA, 2013).

Os dados permitem concluir que a contribuição do sistema para o componente "inspeção e auditoria" é de contribuição parcial. Esse resultado contraria a regra, já que este componente regula a verificação e a averiguação promovidas pelos órgãos de controle externo, em que estes processos são fundamentais para a consecução das atividades e objetivos. A Controladoria-Geral da União (CGU), sempre discutida no viés da execução adequada das atividades públicas, é, pois, o órgão que atenta para a defesa do patrimônio público e o incremento da transparência da gestão, por meio das ações de controle interno, auditoria pública, de correição, prevenção e combate à corrupção e ouvidoria. Nos setores da instituição, a CGU e TCU exercem a averiguação dos modelos de conformidade com as leis de acesso à informação e a acessibilidade social.

Entretanto, quando combinado com o componente anterior, em que observou-se debilidades quanto à atualização de dados públicos e quanto a sua publicidade, elementos fundamentais na auditoria externa, levantam-se dúvidas importantes quanto ao processo em si, pois, o descumprimento levam à punição da autoridade responsável e à tomada de outras medidas cabíveis quando da observância das fragilidades no sistema de transparência nas universidades (BAIRRAL; SILVA, 2013).

Por sua vez, quanto às "Competências e estrutura organizacional", em que foi atribuído "forte contribuição" do e-SIC para a definição da 
transparência pública pelos gestores, evidentemente, observaram-se que esses indicativos, foram seguidos adequadamente, por meio da divulgação de dados, cronogramas, equipes de trabalho, horários de atendimento ao público, canais de contato digital (e-mail e redes sociais) e telefone. Essas informações são preponderantes para que a sociedade possa facilmente localizar os meios de comunicação e interação com as instituições e órgãos públicos, também na busca por satisfazer suas demandas.

Por fim, sobre "Respostas a perguntas mais frequentes da sociedade", $75,8 \%$ dos gestores concordam que, de fato, contribuem para fortalecimento das demandas registradas no e-SIC e no cumprimento dos prazos legais concedidos para a apresentação de respostas por órgão ou instituição pública vinculada ao sistema integrado. Quanto aos questionamentos mais frequentes registrados nos e-SIC, os gestores evidenciaram que as principais dúvidas da sociedade ou instituições são mais direcionadas a questões orçamentárias, programas ou resultados de processos.

Nesse sentido, como muitas dessas informações não são encontradas nas páginas ou são atualizadas, os cidadãos interessados recorrem ao e-SIC como forma de solucionar suas dúvidas. Se, os setores institucionais como define a LAI, alimentassem seus sistemas de informações com esses dados públicos, de maior interesse, certamente o cidadão poderia consultar essas informações nas páginas, tendo acesso por meio de download, planilhas, etc., evitando retrabalho ou tempo dedicado para elucidação dos questionamentos.

O Relatório de Dados Estatístico do e-SIC da Univasf, entre os meses de janeiro a novembro de 2018, evidenciou um registro de 205 pedidos, dos quais $96,59 \%$ já foram respondidos, enquanto que $3,41 \%$ encontram-se dentro dos prazos de tramitação concedidos pela Lei de Acesso à Informação (LAI). Isso demonstra o comprometimento das equipes com os encaminhamentos do e-SIC, já que são fundamentais para o exercício da cidadania e transparência.

Quanto ao "Espaço físico para fornecer informações ao cidadão", cada setor institucional dispõe de um espaço com um profissional capacitado para a apresentação de soluções alternativas para os desafios existentes no contexto social. $78,5 \%$ apresentam em seus setores um espaço onde as políticas e as manifestações podem ser realizadas ou sanadas com os responsáveis pelo tratamento da informação.

Em relação às "Audiências ou de consultas públicas", a maioria dos respondentes apontaram que essa medida "não contribui" para a definição de um cenário em que se substancia a transparência pública amparada pela LAI, a partir da ótica de relevância do e-SIC, enquanto que outros apontaram que este componente não apresenta conformidade com as atividades desenvolvidas nos setores.

\section{Considerações finais}


O artigo buscou analisar como o e-SIC contribui com transparência da Univasf, atendendo a exigências da LAI.

O estudo de caso mostrou que, para a dimensão "Responsabilidades", os gestores apresentaram empregos de procedimentos e mecanismos com uma "forte contribuição" do e-SIC com a transparência pública, conforme ditames da LAI, implicando esses resultados na percepção de que, nos setores institucionais, encontram-se garantidos o acesso facilitado, com a preservação das informações sigilosas, entretanto o que é de interesse público é divulgado com autenticidade, com a perspectiva íntegra e verídica.

Para o acompanhamento dos registros com os pedidos da sociedade e feedback, os gestores utilizam, de forma auxiliar, o e-mail institucional. Ficou clara a relação de compromisso e atenção para consecução das dúvidas via e-SIC e os gestores são enfáticos ao afirmarem dar prioridade às respostas geradas, já que há um prazo de 10 (dez) dias para manifestação do setor quanto ao questionamento do cidadão ou instituição. Esse dado é reforçado pelos relatórios estatísticos disponíveis no banco de dados do sistema do e-SIC, que evidencia que, entre meses de janeiro e novembro de 2018, dos 205 pedidos registrados, 95,19\% encontram-se respondidos dentro do prazo concedido ainda seguem os trâmites para atendimento das demandas.

Quanto à dimensão "Conteúdo e divulgação", notaram-se disparidades importantes de serem discutidas, ainda mais no que compete à divulgação de dados e informações sobre os orçamentos, receitas, despesas, licitações e os programas pertinentes a cada setor institucional, bem como as informações contidas em documentos e registros. Quanto a essas situações, enquanto a LAI apresenta que as informações de perspectiva financeira e de programas implementados devem ser feitos e acessibilizados nos meios digitais, permitindo 0 acesso e acompanhamento por parte da sociedade, estimulando o mecanismo de controle social e transparência, essa exigência, na prática, não é completamente seguida na universidade em estudo.

Indo contra as respostas dos gestores, que confirmaram seguirem essa exigência da lei, quando observado nas páginas institucionais de cada setor, em caráter de observação complementar, as informações e dados públicos encontram, em sua maioria, desatualizados ou não disponibilizados, o que gera uma desconformidade com a LAI. A ausência ou também a desatualização das informações públicas desse porte dificulta o processo de se fazer e construir transparência, além de ferir o direito de acesso à informação.

Além de ser direito de todo e qualquer indivíduo, o acesso à informação é um direito difuso, ou seja, que pertence à coletividade. Isso porque 0 acesso a informações públicas resulta em ganhos para a sociedade. Ter conhecimento de informações permite monitoramento da tomada de decisões pelos governantes, e facilita controle social.

Logo, no tocante à disponibilização de outros materiais, alimentação de forma contínua dos sistemas e atualização dos programas e notícias, é 
preciso, nesta universidade federal, ser estimulada essa consciência de que os setores precisam estar atentos aos ditames, a fim de promover a manutenção dos direitos e garantias dos cidadãos quanto ao acesso facilitado e amplo aos cidadãos interessados, especialmente em relação às informações e dados públicos, com exceção daqueles de caráter sigiloso e protegidos por lei.

$\mathrm{O}$ ato de acessibilizar dados orçamentários, sobre programas, licitações e como os setores empregam os recursos financeiros é também importante para evitar retrabalho e tempo dedicado a solucionar os (RAUPP; ABREU; ABREU, 2015) questionamentos não informados nos meios digitais, o que evitaria em grande parte, desde que disponibilizados nos sítios eletrônicos, que favorece o controle de acesso e pesquisa para manifestação de respostas pelo e-SIC.

Quanto à dimensão de "Meios e mecanismos", os setores disponibilizam espaços para o contato frequente com a sociedade, sendo esta uma das principais contribuições do sistema do e-SIC, disponibilizando horários, canais de diálogo e interação, organogramas e descrição das competências funcionais e os responsáveis por cada execução. Um componente que não foi analisado com maior profundidade por cada gestor foi a questão da consulta e audiência pública, uma vez que o e-SIC não registrou e compartilhou com os gestores questionamentos que contemplassem esse componente.

Dessa forma, os dados evidenciam que 0 e-SIC contribui favoravelmente para a construção de mecanismos de transparência na Univasf. Mais: as dimensões "Responsabilidade" e "Conteúdo" são os conceitos que mais determinam a relevância do tema dentro do contexto da universidade e da importância do e-SIC para o cenário em questão.

Assim, registram-se como principais contribuições: 1 - metodológica - ao possibilitar a análise da contribuição de ferramenta tecnológica, não se limitando a verificação de conformidade ou elaboração de requisitos de transparência, além de focar no processo e as suas implicações, não no resultado. 2 - Situação empírica: foram encontrados, até então, investigações que tratam o e-SIC como um banco de dados de pesquisa a fim de se investigar o perfil cidadão que demanda acesso à informação (ANGELI, 2016); ou pesquisa que busca identificar as maneiras de comunicação do cidadão com o governo (CUNHA; ROSINA; TEIXEIRA, 2015); ou como uma fonte de informações complementares para analisar o progresso na implantação da transparência (ROSA; BAPTAGLIN, 2016); ou como fontes de dados para se pesquisar se órgãos públicos têm conseguido ser transparente (BARROS, 2017); (MENCARINI, 2015); entretanto, não foi localizado estudo com objetivo de pesquisar como ocorre a possível contribuição dessa ferramenta tecnológica para a transparência pública e atendimento das exigências da Lei de Acesso à Informação; 3 - conceitual - o avanço na construção de modelo de análise, iniciado por Cavalcanti, Damasceno e Veras de Neto (2013), agrupando componentes em dimensões de responsabilidade, conteúdo e também divulgação e, meios e mecanismos. 
Como limitação da pesquisa, indica-se um aspecto metodológico já que os resultados não permitem generalização. Por outro lado, registrase, para futuras pesquisas, a necessidade de aplicar o modelo em outros contextos organizacionais, bem como encontrar possíveis correlações entres os componentes das dimensões.

\section{Referências}

ANGELI, Alzira. Transparência e acesso à informação: quem é o cidadão que demanda a abertura de informações públicas no Brasil?, Revista Eletrônica de Ciência Política, v. 7, n. 2, 2016.

ANGÉLICO, F. Lei de acesso à informação pública e seus possíveis desdobramentos para a accountability democrática no Brasil. 2012. 133p. Tese de Doutorado. Escola de Administração de Empresas de São Paulo Fundação Getúlio Vargas. São Paulo, 2012.

AIROLDI, C.; SILVEIRA, M. A transparência na gestão pública como instrumento de controle social. Revista Eletrônica do Curso de Ciências Contábeis, 2015, v. 4, n.6, p. 71-91.

BAIRRAL, M.; SILVA, A.; ALVES, F. Transparência no setor público: análise dos relatórios de gestão anuais de entidades públicas federais no ano de 2010. Revista de Administração Pública-RAP, v. 49, n. 3, 2015.

BARBOSA, A. Perfil da produção científica brasileira sobre o governo eletrônico. Revista Eletrônica Gestão e Serviços, 2017, v. 8, n. 1, p. 17851810.

BARDIN, L. Análise de conteúdo. Lisboa: Edições 70, 2009.

BARROS, Savia Rodrigues Martins. A transparência passiva na Universidade Federal da Paraíba. 2017. 87p. Tese de Mestrado, Mestrado Profissional em Políticas Públicas, Gestão e Avaliação do Ensino Superior Universidade Federal da Paraíba. João Pessoa, 2017.

CARLI, D.; FACHIN, G. Lei de Acesso à Informação nos municípios do extremo oeste de Santa Catarina. Em Questão, v. 22, n. 1, 2016.

CAVALCANTI, J.; DAMASCENO, L.; NETO, M. Observância da lei de acesso à informação pelas autarquias federais do Brasil. Perspectivas em ciência da informação, v. 18, n. 4, p. 112-126, 2013.

COELHO, E. Governo eletrônico e seus impactos na estrutura e na força de trabalho das organizações públicas. Revista do Serviço Público, v. 52, n. 2, p. $110,2001$.

CORDEIRO, A. et al. Governo eletrônico e redes sociais: informação, participação e interação. RECIIS - R. Eletr. de Com. Inf. Inov. Saúde, Rio de Janeiro, v.6, n.2, Jun. , p. 1-8, 2012.

CRUZ, C. et al. Transparência da gestão pública municipal: um estudo a partir dos portais eletrônicos dos maiores municípios brasileiros. Revista de Administração Pública, v. 46, n. 1, p. 153-176, 2012. 
CUNHA, Maria Alexandra Viegas Cortez da; ROSINA, Mônica Steffen Guise; TEIXEIRA, Marco Antonio Carvalho. Panorama da transparência governamental no Brasil. CEAPG-Centro de Estudos em Administração Pública e Governo (EAESP) e GEPI-Grupo de Ensino e Pesquisa em Inovação (Direito SP), 2015.

DINIZ, E., et al. O governo eletrônico no Brasil: perspectiva histórica a partir de modelo estruturado de análise. RAP-Revista de Administração Pública , v.43, n. 1, p. 23-48, 2009.

FIGUEIREDO, V.; SANTOS, Waldir J. Transparência e controle social na gestão pública. Temas de Administração Pública, v. 8, n. 1, 2013.

GAMA, J.; RODRIGUES, G. Transparência e acesso à informação: um estudo da demanda por informações contábeis nas universidades federais brasileiras. TransInformação, v.28, n.1, p.47-57, 2016.

GAMA, M. et al. A lei de acesso à informação em instituições federais de ensino superior: investigação na cultura organizacional da Universidade Federal Rural da Amazônia. Perspectivas Contemporâneas, v. 12, n. 3, p. 135-154, 2017.

JARDIM, J. A Lei de Acesso à Informação Pública: dimensões políticoinformacionais. Tend. Pesq. bras. Ci. Inf., Brasília, v. 5, n. 1, 2013.

JUSTEN FILHO, M. Comentários à Lei de licitações e contratos administrativos: Lei 8.666/1993. São Paulo: Editora Revista dos Tribunais, 2014.

LOPES, C. Acesso à informação pública. Biblioteca digital da câmara, 2006. Disponível em: http://bd.camara.gov.br/bd/handle/bdcamara/1709 . Acesso em: 02 mar. 2018.

MARTINS, P. Acesso à informação: direito fundamental e instrumental. Acervo, v. 24, n. 1, jan-Jun, p. 233-244, 2012.

MEDEIROS, S.; MAGALHÃES, R.; PEREIRA, J. Lei de acesso à informação: em busca da transparência e do combate à corrupção. Informação \& informação, v. 19, n. 1, p. 55-75, 2013.

MENCARINI, Fabrizio. Transparência nos bancos públicos brasileiros: um estudo sobre a implementação da Lei de Acesso à Informação (LAI) no Banco do Brasil (BB), Caixa Econômica Federal (CEF) e Banco Nacional de Desenvolvimento Econômico e Social (BNDES). 2015. 232. Escola de Administração de Empresas de São Paulo - Fundação Getúlio Vargas. São Paulo, 2015.

PORTELLA, A.; CÔRTES, A. Análise crítica do acesso à informação pública nos municípios baianos com mais de 100 mil habitantes. Revista de Direito da Cidade, v. 7, n. 3, p. 1092-1111, 2015.

RAUPP, F.; PINHO, Jo. Prestação de contas nos portais eletrônicos de Assembleias Legislativas: estudo após a Lei de Acesso à Informação. Gestão \& Planejamento-G\&P, v. 15, n. 1, 2014. 
RAUPP, F.; ABREU, E.; ABREU, M. Disponibilização de informações à sociedade em meios eletrônicos: um estudo nas prefeituras dos maiores municípios brasileiros. Revista Catarinense da Ciência Contábil, v. 14, n. 42, 2015.

ROCHA, H. Transparência e accountability no estado democrático de direito: reflexões à luz da lei de acesso à informação. Revista do Tribunal de Contas do Estado de Minas Gerais, p. 84-94, 2013.

RODRIGUES, A.; MARCONDES, C. Universidades federais brasileiras: influências das políticas públicas de informação na criação de seus repositórios. Páginas a\&b: arquivos e bibliotecas, n.esp., p.46-58, 2018.

ROSA, Tatiana Costa; BAPTAGLIN, Leila Adriana. O progresso na implantação da transparência informacional ativa no estado de Roraima: o caso do IFRR e da UFRR. Ciência da Informação em Revista, Maceió, v. 3, n. 3, p. 9-19, set./dez. 2016.

SANTOS, E. Desenvolvimento e implementação de padrões de interoperabilidade em governo eletrônico no Brasil. 2008. Tese de Doutorado. Universidade de São Paulo, 2008.

SOUZA, F. et al. Índice de transparência municipal: um estudo nos municípios mais populosos do Rio Grande do Norte. Revista de Gestão, Finanças e Contabilidade, v. 3, n. 3, p. 94, 2013.

VIEIRA, M.; MONTENEGRO JUNIOR, C. A busca pela eficiência no serviço público, através da lei de acesso à informação e as relações com o aprimoramento da gestão da informação. Saber Humano: Revista Científica da Faculdade Antonio Meneghetti, v. 6, n.8, p. 121-135, 2016. YIN, Robert K. Estudo de Caso: Planejamento e Métodos. Porto Alegre: Bookman, 2015.

ZORZA, L.; RODRIGUES, G.; GAMA, J. Transparência na gestão de universidades públicas brasileiras. In: SÁNCHEZ, Aurelio Villa (Ed.)Tendencias actuales de las transformaciones de las universidades en una nueva sociedad digital. Foro Internacional de Innovación Universitaria, 2018. p. 863-878. 